•编者按・

\title{
自然杂交：生物多样性的梦魄还是盛宴?
}

\author{
严岳鸿 $^{1^{*}}$ 康 明 $^{2}$ 马永鹏 ${ }^{3}$ 周仁超 ${ }^{4}$ \\ 1 (上海辰山植物园, 中国科学院上海辰山植物科学研究中心, 上海 201602) \\ 2 (中国科学院华南植物园, 中国科学院植物资源保护与可持续利用重点实验室, 广州 510650) \\ 3 (中国科学院昆明植物研究所, 昆明 650201) \\ 4 (中山大学生命科学学院, 广州 510275)
}

\section{Natural hybridization: a nightmare or a delight to biodiversity?}

\author{
Yuehong Yan $^{1 *}$, Ming Kang ${ }^{2}$, Yongpeng Ma ${ }^{3}$, Renchao Zhou ${ }^{4}$ \\ 1 Shanghai Chenshan Plant Science Research Center, Chinese Academy of Sciences; Shanghai Chenshan Botanical \\ Garden, Shanghai 201602 \\ 2 Key Laboratory of Plant Resources Conservation and Sustainable Utilization, South China Botanical Garden, Chinese \\ Academy of Sciences, Guangzhou 510650 \\ 3 Kunming Institute of Botany, Chinese Academy of Sciences, Kunming 650201 \\ 4 School of Life Sciences, Sun Yat-sen University, Guangzhou 510275
}

2016 年, 中国科学院昆明动物研究所的研究人 员发现，北宋皇帝宋徽宗赵佶的御题画《芙蓉锦鸡 图》中的锦鸡是一个杂交个体, 这是距今约 900 年 前鸟类杂交的最早记录。考虑到红腹锦鸡(Chrysolophus pictus)和白腹锦鸡(C. amherstiae)在野外和 圈养下都有杂交记录, 研究人员推测画家画的这只 锦鸡可能有两种来源, 一种是已经圈养的红腹锦鸡 和白腹锦鸡杂交产生的后代; 一种是野外自然杂交 个体(Peng et al, 2016)。杂交锦鸡兼具两个亲本的优 良性状，从庶民百姓到皇帝贵冒自然都是喜爱的; 但是, 对科学家来说这个异类的出现可能是一个不 小的困惑。

对传统分类学家来说，兼具父母双方性状特征 的自然杂交种(hybrids, hybrid species)的出现会模糊 自然物种之间的界限; 对系统生物学家来说, 完美 的生命之树会因为杂交而成为杂乱无章的生命之 网; 而对保护生物学家来说, 自然杂交种介导的渐 渗或回交会侵蚀物种的纯粹性。

自然杂交是指在自然条件下具有显著不同可 遗传性状的两个物种甚至是生态适应上悬殊很大 的两个居群间个体的成功交配(洪德元, 1990; Arnold，1992)。通常大部分杂交后代因为不育而被淘 汰, 但因无融合生殖的发生和异源多倍体的形成,
自然杂交种在自然界普遍存在(Arnold, 1992, 1997)。 由于植物中广泛存在的无融合生殖现象, 三倍体或 多倍体的自然杂交种往往可以通过无融合生殖等 机制繁衍后代, 这对植物的物种形成具有重要意义 (洪德元, 1990)。此外, 同倍体杂交物种形成的例子 也越来越多(Feliner et al, 2017)。2016 年 11 月, Science 发表综述“Shaking up the Tree of Life”, 详述 了由于自然杂交和基因渐渗引起的网状进化对传 统的生命之树理论提出了挑战(Pennisi, 2016)。

虽然中国人在 900 年前的画作中就记录了物种 之间的杂交现象, 但是中国动、植物志中记载的自 然杂交种并不多。在动物中, 昆虫的自然杂交极为 普遍，但中国的昆虫学家目前多关注新物种的发现 和发表, 还未对自然杂交物种予以足够的关注, 因 此本专辑也没有征集到动物学领域的研究工作, 成 为这个专辑的遗憾。在植物中, 《中国植物志》完 成后, 留给现世一个长长的植物物种清单。然而, 对这个国家植物志物种数世界之最的清单, 中外植 物学家仍有大量的疑虑, 特别是大量似是而非的物 种, 我们不清楚这里包含多少自然杂交种。2016 年 11 月 11 日, 在中国科学院生物多样性委员会的组 织下，召开了“中国首届自然杂交与生物多样性研 讨会”并组织了这个专辑。希望本专辑的出版能吸

\footnotetext{
* 通讯作者 Author for correspondence. E-mail: yhyan@sibs.ac.cn
} 
引更多研究人员去触及中国生物多样性中的秘境 一自然杂交。

对自然杂交后代的命运已有很多讨论, 虽然现 实中大部分杂交后代为自然界所淘汰, 但是杂交仍 然是物种形成机制中不可忽视的因素。本专辑中, 王玉国(2017)简述了自然杂交与物种形成的研究历 史和基因组时代杂交与物种形成研究的新进展; 毛 建丰等(2017)则以高通量测序技术为核心, 结合表 型、群体遗传学和系统发育等多种分析手段, 联系 实际案例, 系统介绍了如何检验自然杂交的存在; 然而, 自然杂交的发生不仅可以造成遗传上的差异, 也会造成表观遗传上的变化, 李霖锋和刘宝(2017) 介绍了表观遗传——主要是指独立于遗传变异之 外的一种可以影响生物发育的遗传信息或无法用 DNA 序列变异解释但却有基因功能变异的染色体 修饰一一在植物杂交与多倍化过程中所起到的作 用, 并基于在拟南芥(Arabidopsis thaliana)、水稻 (Oryza sativa)和芸薹属物种(Brassica spp.)中已有的 实例, 探讨了表观遗传变异与表型革新的相关性。 希望读者能从这 3 篇综述中全面了解自然杂交的研 究历史、方法和前沿。

生殖隔离是保持物种独立性的基础, 而自然杂 交则会打破这道屏障而模糊物种的边界。魏宇昆等 (2017) 研究了浙江天目山同域分布的舌瓣鼠尾草 (Salvia liguliloba)和南丹参(S. bowleyana)强烈的传 粉前隔离机制和微弱的传粉后隔离机制, 致使在亲 缘关系较近且需借助共同传粉者完成异交的两种 鼠尾草, 以花部传粉结构的显著差异形成强烈的机 械隔离, 从而避免了同域分布、花期重叠的物种间 的花粉干扰和自然杂交, 维持了物种种群遗传结构 的稳定性。张小龙等(2017)研究了苦苣苔科牛耳朵 (Primulina eburnea)和马坝报春苣苔 (P. mabaensis) 两个物种不同的生殖隔离机制, 结果显示当两个物 种传粉前后隔离机制未彻底发育时, 物种间的自然 杂交将会发生, 自然杂交后代的个体将会出现。两 个精巧的案例研究显示了有花植物的生殖隔离在 自然杂交物种形成中的重要意义, 生动地说明了生 殖隔离是保持物种独立性和促进物种多样性的基 础。然而, 对大部分偋类植物来说, 孢子同型的共 同特征意味着偋类植物相对微弱的生殖隔离机制 和自然杂交在穙类植物中的普遍发生。常艳芬(2017) 通过对铁角蒝科植物染色体数据的分析, 探讨了硕
类植物中普遍发生的多倍化现象和网状进化机制。

检测自然杂交种的存在、揭示自然杂交发生的 过程和规律是当前中国生物多样性研究中最为基 础和艰难的工作, 多学科的证据链的结合方能全面 了解自然杂交种出现的前世今生。郑硕理等(2017) 和周秋杰等(2017)分别基于核 DNA 序列、叶绿体 DNA 序列和形态特征数据的整合分析, 通过强有 力的证据揭示了中国杜鹃花属(Rhododendron)和野 牡丹属(Melastoma)新发现的自然杂交现象。谢艳萍 等(2017)则通过叶绿体 DNA 和核 DNA 序列分析, 以及人工授粉实验, 首次揭示了偏花报春(Primula secundiflora $)$ 和海仙报春 $(P$. poissonii) 在 3 个同域居 群中出现的不对称杂交机制; 而田代科等(2017)则 从自然地理分布、形态学特征、分子生物学检测和 杂交试验等多个方面, 系统总结了中国秋海棠属 (Begonia)的自然杂交发生及其特点。

自然杂交在植物界的普遍发生预示着网状进 化的可能性，因此传统的理想中的生命之树则可能 演变成复杂的生命进化网络。舒江平等(2017)通过对 福建观音座莲(Angiopteris fokiensis)转录组序列的测 序, 比较了莱茵衣藻(Chlamydomonas reinhardtii)、 小立碗藓 (Physcomitrella patens)、江南卷柏 (Selaginella moellendorffii)和欧洲云杉(Picea abies) 等植物的全基因组序列, 利用系统基因组学的方法 重构了陆生植物的系统发育进化关系。结果发现, 不同的分析策略将得到不同的系统发育拓扑结构: 基于 1,668 个直系同源基因的单独分析得到 15 种不 同的拓扑结构; 而系统发育网络分析结果显示, 藻 类、苔藓、石松类、种子植物和偋类植物等 5 个类 群间在进化的早期可能存在非常复杂的网状进化 关系。

2007年 Nature 文章估计，全世界至少已有 $10 \%$ 的动物和 $25 \%$ 的植物经历了自然杂交起源(Mallet, 2007)。近年来，不仅有大量新的自然杂交种被发现， 而且还有越来越多的人们熟悉的物种被证实为自 然杂交起源，从而使物种之间的演化关系不再是过 去描述的简单的二歧分支线性关系，而是形成复杂 的网络。虽然这些复杂的网状进化关系可能是物种 演化的真实表现, 并且对研究物种形成和演化具有 重要价值, 却给分类学带来了越来越多的困扰, 逐 渐成为分类学家的哥梦(Dejaco et al, 2016)。不仅如 此, 广泛的杂交后代与亲本回交导致的基因渐渗, 


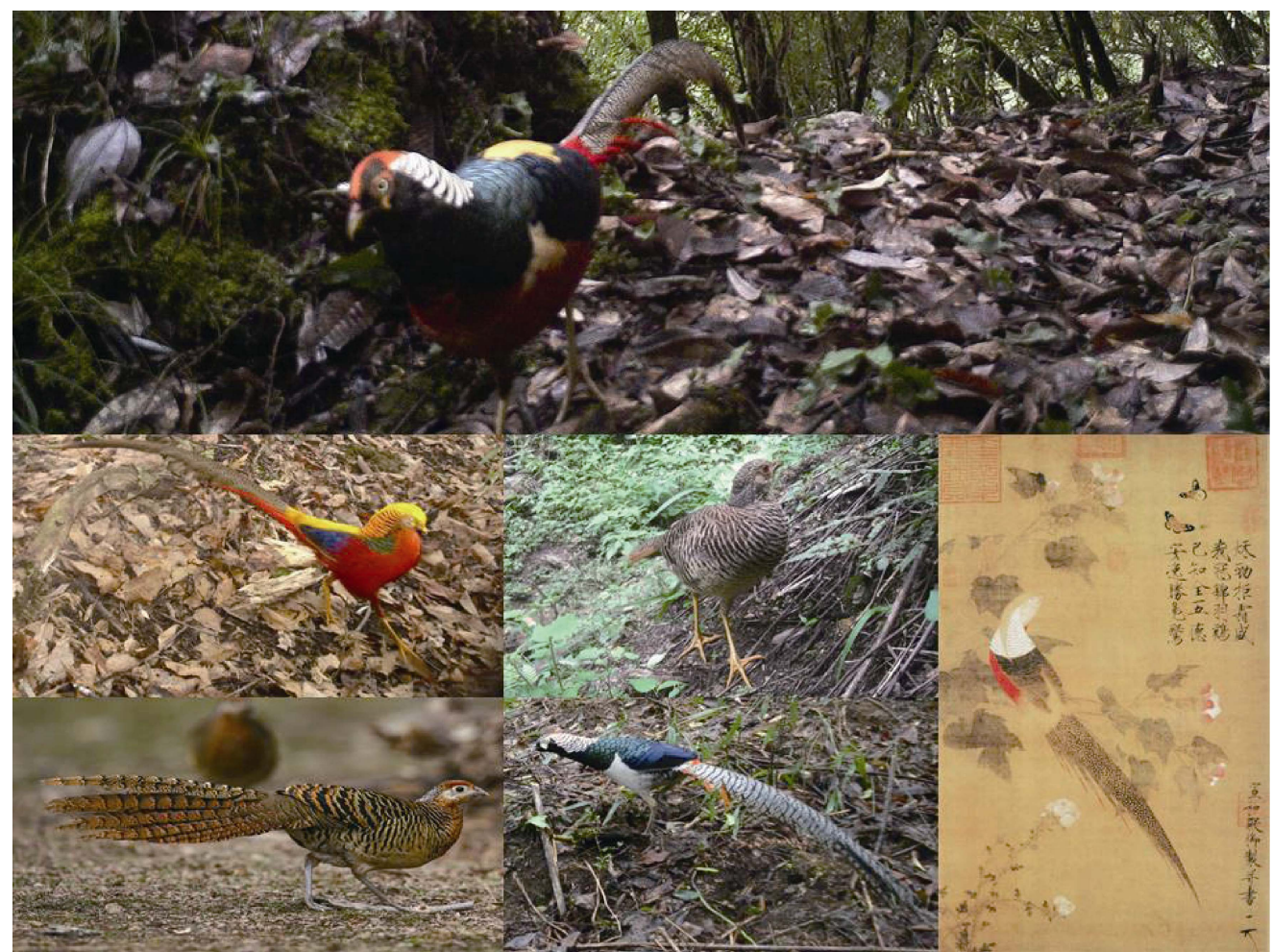

图 1 红腹锦鸡(左中, 中央)、白腹锦鸡(左下, 中下)的成年雌雄个体, 以及红外相机在野外记录到的野生杂交个体(上图, 成 年雄性, 四川鞍子河保护区)。红腹锦鸡和白腹锦鸡在我国西南邛崃山等地分布区重叠, 存在天然杂交现象, 杂交个体兼具双 方亲本的形态特征, 在 900 多年前北宋徽宗赵佶传世名画《芙蓉锦鸡图》(右下)中即被描绘。(供图: 李星/北京大学、保护国 际基金会、鞍子河保护区、IBE)

Fig. 1 Golden pheasant (Chrysolophus pictus, middle left and central), lady Amherst's pheasant (C. amherstiae, lower left and lower middle) and a male hybrid individual (upper) which is recently captured by camera-trap in Anzihe Nature Reserve, Sichuan Province, representing chimeric morphological characteristics from both parental species. Such hybrid pheasant has been described in an ancient painting (lower right) by Emperor Huizong dated back to the 12th century in China. (animal picture credit: Sheng Li / Peking University, Conservation International, Anzihe Nature Reserve, IBE)

可能会给祖先物种或亲本的生存造成威胁(周秋杰 等，2017)。因此，对自然杂交物种或杂交后代是否 需要保护成为近年来国际上争议的热点问题。商辉 和严岳鸿(2017)从遗传多样性、物种多样性和生态 系统多样性等三个方面论述了自然杂交种在进化 和生态过程中的重要作用, 并结合近年来自然杂交 的研究和保护案例, 提出自然杂交种的保护策略和 建议。

《芙蓉锦鸡图》中的杂交锦鸡不仅仅生活在皇 帝的御画中, 同样也生活在今天的自然界, 北京大 学的李晟在野外用红外相机也捕捉到了野生杂交 个体(图 1)。虽然是个异类, 但却是自然界的奇迹。 同样的, 它需要一个合法的名称而不仅仅被称为杂 交种, 它需要找到父母而不是仅仅游离于家族之外, 它需要人类的保护和关爱而不仅仅是被当作异类
甚至被清除。希望读者通过阅读本期专辑能从自然 杂交的角度对生物多样性有一个新的认识。

致谢: 北京大学李晟博士、保护国际基金会、鞍子 河保护区、IBE等提供了本文插图中的图片, 李晟 博士为本文的插图进行了描述, 在此一并致谢。

\section{参考文献}

Arnold ML (1992) Natural hybridization as an evolutionary process. Annual Review of Ecology, Evolution, and Systematics, 37, 237-261.

Arnold ML (1997) Natural Hybridization and Evolution. Oxford University Press, Oxford.

Chang YF (2017) Polyploidy and the formation of species diversity in Aspleniaceae. Biodiversity Science, 25, 621-626. (in Chinese with English abstract) [常艳芬 (2017) 铁角䓲科 的多倍化与物种多样性形成. 生物多样性, 25, 621-626.] 
Dejaco T, Gassner M, Arthofer W, SchlickSteiner BC, Steiner FM (2016) Taxonomist's nightmare ... evolutionist's delight: an integrative approach resolves species limits in jumping bristletails despite widespread hybridization and parthenogenesis. Systematic Biology, 65, 947-974.

Feliner GN, Álvarez I, Fuertes-Aguilar J, Heuertz M, Marques I, Moharrek F, Piñeiro R, Riina R, Rosselló JA, Soltis PS, Villa-Machío I (2017) Is homoploid hybrid speciation that rare? Heredity, 118, 513-516.

Hong DY (1990) Plant Cytotaxonomy, pp. 159-160. Science Press, Beijing. (in Chinese) [洪德元 (1990) 植物细胞分类 学, 159-160页. 科学出版社, 北京.]

Li LF, Liu B (2017) The roles of epigenetic variation in plant hybridization and polyploidization. Biodiversity Science, 25, 600-607. (in Chinese with English abstract) [李霖锋, 刘宝 (2017) 表观遗传变异在植物杂交与多倍化过程中的作 用. 生物多样性, 25, 600-607.]

Mallet J (2007) Hybrid speciation. Nature, 466, 279-283.

Mao J-F, Ma YP, Zhou RC (2017) Approaches used to detect and test hybridization: combining phylogenetic and population genetic analyses. Biodiversity Science, 25, 577-599. (in Chinese with English abstract) [毛建丰, 马永鹏, 周仁超 (2017) 结合系统发育与群体遗传学分析检验杂交是否存 在的技术策略. 生物多样性, 25, 577-599.]

Peng MS, Wu F, Murphy RW, Yang XJ, Zhang YP (2016) An ancient record of an avian hybrid and the potential uses of art in ecology and conservation. Ibis, 158, 444-445.

Pennisi E (2016) Shaking up the Tree of Life. Science, 54, 817-821.

Shang H, Yan YH (2017) Natural hybridization and biodiversity conservation. Biodiversity Science, 25, 683-688. (in Chinese with English abstract) [商辉, 严岳鸿 (2017) 自然 杂交与生物多样性保护. 生物多样性, 25, 683-688.]

Shu JP, Liu L, Shen H, Dai XL, Wang QX, Yan YH (2017) The complex reticulate evolutionary relationships of early terrestrial plants as revealed by phylogenomics analysis. Biodiversity Science, 25, 675-682. (in Chinese with English abstract) [舒江平, 刘莉, 沈慧, 戴锡玲, 王全喜, 严岳鸿 (2017) 基于系统基因组学分析揭示早期陆生植物的复杂 网状进化关系. 生物多样性, 25, 675-682.]

Tian DK, Li C, Xiao Y, Fu NF, Tong Y, Wu RJ (2017) Occurrence and characteristics of natural hybridization in Begonia in China. Biodiversity Science, 25, 654-674. (in Chinese with English abstract) [田代科, 李春, 肖艳, 付乃峰, 童 毅, 吴瑞娟 (2017) 中国秋海棠属植物的自然杂交发生 及其特点. 生物多样性, 25, 654-674.]

Wang YG (2017) Natural hybridization and speciation. Biodiversity Science, 25, 565-576. (in Chinese with English abstract) [王玉国 (2017) 自然杂交与物种形成. 生物多样性, 25, 565-576.]

Wei YK, Huang YB, Li GB (2017) Reproductive isolation in sympatric Salvia species sharing a sole pollinator. Biodiversity Science, 25, 608-614. (in Chinese with English abstract) [魏宇昆, 黄艳波, 李桂涁 (2017) 同域分布共享传 粉者的鼠尾草属植物的生殖隔离. 生物多样性, 25 , 608-614.]

Xie YP, Zhao JL, Zhu XF, Li L, Li QJ (2017) Asymmetric hybridization of Primula secundiflora and P. poissonii in three sympatric populations. Biodiversity Science, 25, 647-653. (in Chinese with English abstract) [谢艳萍, 赵建 立, 朱兴福, 李莉, 李庆军 (2017) 偏花报春和海仙报春 3个同域居群的不对称杂交. 生物多样性, 25, 647-653.]

Zhang XL, Yang LH, Kang M (2017) Post-pollination reproductive isolation of sympatric populations of Primulina $e b$ urnea and P. mabaensis (Gesneriaceae). Biodiversity Science, 25, 615-620. (in Chinese with English abstract) [张小 龙, 杨丽华, 康明 (2017) 牛耳朵和马坝报春菅苔同域居 群授粉后的生殖隔离. 生物多样性, 25, 615-620.]

Zheng SL, Tian XL, Huang CL, Wang LJ, Feng Y, Zhang JL (2017) Molecular and morphological evidence for natural hybridization between Rhododendron decorum and $R$. delavayi (Ericaceae). Biodiversity Science, 25, 627-637. (in Chinese with English abstract) [郑硕理, 田晓玲, 黄承玲, 王灵军, 冯元, 张敬丽 (2017) 结合分子手段和形态分析 验证大白杜鹃与马亚杜鹃的自然杂交. 生物多样性, 25 , 627-637.]

Zhou QJ, Cai YC, Ng WL, Wu W, Dai SP, Wang F, Zhou RC (2017) Molecular evidence for natural hybridization between two Melastoma species endemic to Hainan and their widespread congeners. Biodiversity Science, 25, 638-646. (in Chinese with English abstract) [周秋杰, 蔡亚城, 黄伟 伦, 吴伟, 代色平, 王峰, 周仁超 (2017) 野牡丹属两个 海南特有种与同属广布种自然杂交的分子证据. 生物多 样性, 25, 638-646.] 